\section{A Genética das Sindromes Hipertensivas Endócrinas}

revisão

\section{RESUMO}

A hipertensão arterial sistêmica está associada a altos índices de morbimortalidade e constitui um dos grandes problemas de saúde pública no mundo, dada sua alta prevalência e baixa porcentagem de controle com os tratamentos adotados. Este último problema é justificado, pelo menos em parte, porque ainda utilizamos medidas empíricas para o tratamento, ao invés de uma abordagem específica para cada caso. Os determinantes primários da hipertensão permanecem desconhecidos na maioria dos pacientes, ao qual damos o nome genérico de hipertensão essencial ou primária. Estas limitações estão alicerçadas pelo conceito de que a hipertensão é uma doença complexa, poligênica em sua maioria e com direta interação com fatores ambientais, tais como dieta, ingestão de sal e obesidade, entre outras. A utilização de técnicas de biologia molecular tem trazido uma enorme contribuição para a compreensão de fenômenos biológicos complexos. Sabe-se que em uma minoria dos casos a hipertensão arterial ocorre pela presença de mutações específicas, ditas formas mendelianas, que resultam em ganho de função de transportadores do néfron distal, bem como de vários componentes do sistema reninaangiotensina-aldosterona com conseqüente retenção excessiva de sal. De interesse particular na endocrinologia, estas síndromes podem ser divididas em aumento na produção ou na atividade dos mineralocorticóides e estarão expostas nesta revisão. (Arq Bras Endocrinol Metab 2004;48/5:659-665)

Descritores: Hipertensão arterial; Hiperaldosteronismo supressível por glicocorticóides; Excesso aparente de mineralocorticóides; Síndrome de Liddle; Feocromocitoma; Neoplasia endócrina múltipla

\begin{abstract}
Genetic Aspects of Endocrine Hypertensive Disorders.

Arterial hypertension is associated with high morbidity and mortality indices and constitutes a major health problem worldwide, specially due to its high prevalence and low rate of control with the standard treatment. This problem can be explained, at least in part, because we still use empiric measures when choosing treatment options, instead of a rational approach for each case. The determinants of the hypertension remain unknown in the majority of patients and is designated as essential or primary hypertension. Hypertension is a model of complex disease in which several genes may be affected and influenced by a variety of environmental interactions, such as diet, salt and obesity, among others. The use of molecular biology strategies is offering new opportunities for the understanding of complex biological phenomena, like hypertension. However, only in a minority of cases, arterial hypertension occurs by individual specific mutations, called mendelian forms of hypertension, involving distal nefron transporter gene products. These syndromes are of particular interest since they highlight the importance of cell pathways that can be affected in the more common forms of
\end{abstract}

Luciano F. Drager José Eduardo Krieger

Unidade de Hipertensão do InCor (LFD) - HCFMUSP $e$ Departamento de Clinica Médica (JEK) - LIMI3 FMUSP, São Paulo, SP. 


\section{hypertension. (Arq Bras Endocrinol Metab 2004;48/5:659-665) \\ Keywords: Arterial hypertension; Glucocorticoid- suppressible hyperaldosteronism; Apparent miner- alocorticoid excess; Liddle's syndrome; Pheochro- mocytoma; Multiple endocrine neoplasia}

A HIPERTENSÃO ARTERIAL SISTÊMICA constitui um dos grandes problemas de saúde pública no mundo, dada sua alta prevalência (no Brasil, de 22 a $44 \%$ ) e uma baixa porcentagem de controle com os tratamentos adotados (nos EUA, em torno de 30\%). Entretanto, a despeito da intensa investigação clínica, os determinantes primários da hipertensão permanecem desconhecidos na maioria dos pacientes, e por isso é designada hipertensão essencial ou primária. Conseqüentemente, são utilizadas medidas empíricas para o tratamento ao invés de uma abordagem racional para cada caso. Estas limitações estão alicerçadas pelo conceito de que a hipertensão é uma doença complexa, poligênica, que sofre grande influência de uma variedade de fatores ambientais, tais como dieta, ingesta de sal e obesidade, entre outras.

A utilização de estratégias de biologia molecular tem trazido novas oportunidades para a compreensão de fenômenos biológicos complexos. Recentemente, foram identificadas mutações isoladas que estão associadas ao surgimento de formas mendelianas raras de hipertensão arterial. Estas mutações resultam em ganho de função de transportadores do néfron distal que resultam em uma excessiva retenção de sal. A compreensão destas síndromes é particularmente importante, pois elas devem sinalizar vias celulares que podem estar envolvidas nas formas mais comuns de hipertensão arterial primária.

\section{SÍNDROMES HIPERTENSIVAS ENDÓCRINAS}

\section{Aldosteronismo Supressível por Glicocor- ticóide}

O aldosteronismo supressível por glicocorticóide é uma forma mendeliana de hipertensão, no qual a herança de uma única alteração genética é responsável pelo surgimento da hipertensão. Ela foi inicialmente descrita em 1966 por Sutherland, Ruse e Laidlaw em 1966 (2) e de forma independente por New e Peterson em 1967 (3). Tem um traço autossômico dominante, caracterizado por um início precoce de hipertensão mediado via receptor mineralocorticóide. Bioquimicamente, associa-se com a hipocalemia variável, supressão da atividade plasmática de renina e altos níveis dos esteróides 18-hidroxicortisol e 18-oxocorti- sol (4). A característica desta forma mendeliana de hipertensão é o controle aberrante da aldosterona e dos esteróides pelo ACTH de forma mais intensa do que a supressão pela angiotensina II. Conseqüentemente, a secreção de aldosterona pode ser suprimida pela administração de glicocorticóides.

Estudos genéticos indicam forte ligação do fenótipo bioquímico intermediário de níveis urinários de 18-oxocortisol a marcadores genéticos derivados do gene candidato aldosterona sintase. A investigação deste gene evidenciou um achado surpreendente: $\mathrm{O}$ alelo do aldosteronismo supressível por glicocorticóide apresenta uma cópia adicional semelhante ao gene da aldosterona sintase (4). Este gene é estritamente relacionado com outro gene envolvido com a biossíntese de esteróides - gene da $11-\gamma$-hidroxilase. Estes dois genes são idênticos na seqüência de DNA em 95\%, com limites idênticos intron-exon e localizados no cromossoma 8 (5). Sendo estes dois genes tão estreitamente similares e arranjados muito próximos, uma recombinação aberrante entre eles poderia ocorrer - e ocorre (figura 1). Desta forma, em um dos cromossomos são retidas cópias normais da $11-\gamma$-hidroxilase e aldosterona sintase, enquanto que no outro cromossomo ocorre a formação de uma quimera que resulta na formação de um novo gene com a porção regulatória proveniente do gene da $11-\gamma$-hidroxilase e a porção codificadora do gene aldosterona sintase. Em conseqüência, a produção de aldosterona neste alelo será controlada por sinais que normalmente controlam a síntese de glicocorticóides. Análises moleculares deste evento confirmam a ocorrência de um crossing over desigual, com porções da terminação 5' do gene da $11-\gamma$-hidroxilase fundidos a seqüências mais distais do gene da aldosterona sintase.

Mas como o gene quimérico participa na expressão fenotípica do aldosteronismo supressível por

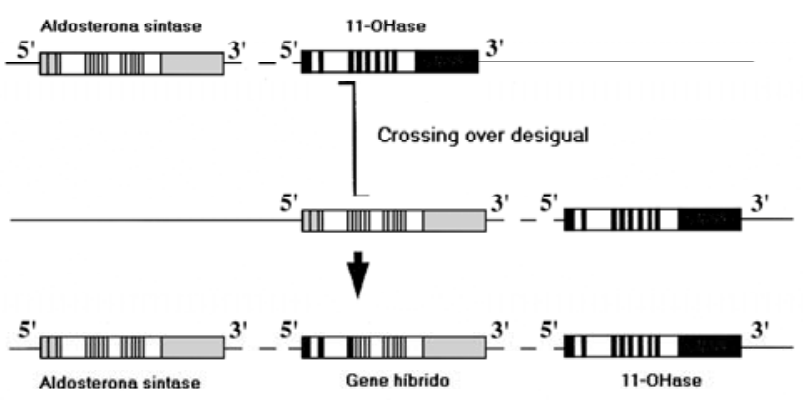

Figura 1. Formação do gene híbrido (quimérico) pelo crossing over desigual entre o gene da aldosterona sintase e $11 \gamma$-hidroxilase (11-OHase). Um dos cromossomas formados carreará três genes em vez de dois; o gene duplicado fundirá seqüências dos dois genes no sítio de recombinação. (adaptado de ref. 4)

Arq Bras Endocrinol Metab vol $48 n^{\circ} 5$ Outubro 2004 

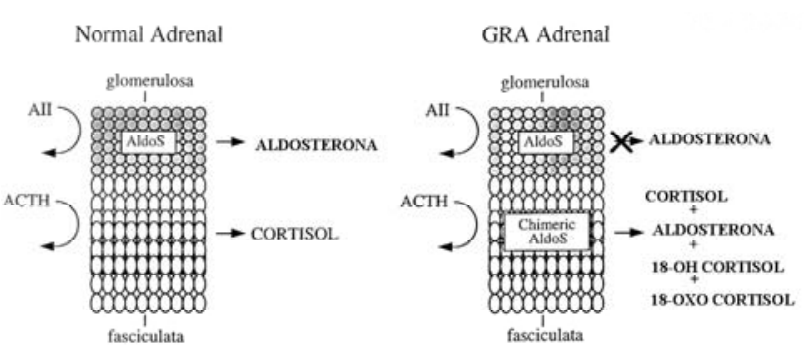

Figura 2. Modelo da glândula adrenal no aldosteronismo supressivel por glicocorticóide (GRA). O gene quimérico destacado na figura anterior é expresso na região fasciculada da glândula adrenal, devido a seqüências regulatórias responsivas ao ACTH do gene da 11-y-hidroxilase; o produto da codificacão tem atividade enzimática da aldosterona sintase (AldoŞ). Expressão ectópica desta atividade resulta na síntese de 18-hidroxicortisol e 18-oxocortisol usando o cortisol como substrato. Portanto, a aldosterona também é produzida pela zona fasciculada pelo estímulo do corticosteróide. A II - angiotensina II. (adaptado de ref. 24)

glicocorticóide? O gene quimérico tem padrão de expressão semelhante ao gene da $11-\gamma$-hidroxilase, sendo altamente expresso na região fasciculada da glândula adrenal, e é basicamente controlado sob o estímulo dos níveis de ACTH, que resultará em alterações na atividade enzimática da aldosterona sintase. Como resultado, a enzima pode utilizar o cortisol como substrato para a síntese de 18-hidroxicortisol e 18-oxocortisol. Além disto, devido aos altos níveis de corticosterona na região fasciculada, a aldosterona será produzida também nesta zona adrenal (figura 2) e poderá ser suprimida por glicocorticóides, que é o tratamento de escolha para este tipo de hipertensão.

Vale destacar que fazer o diagnóstico de aldosteronismo supressível por glicocorticóide é importante por duas razões principais: primeiro, pacientes com aldosteronismo supressível por glicocorticóide são freqüentemente refratários ao tratamento anti-hipertensivo convencional e respondem de maneira efetiva com uma terapêutica guiada para a anormalidade genética. Estes pacientes apresentam alta freqüência de lesões de órgãos-alvo, tais como acidente vascular cerebral. Segundo, muitos casos podem ser diagnosticados a partir de um caso-índice, contribuindo para uma abordagem e terapêutica precoces.

\section{Síndrome do Excesso Aparente de Mineralocorticóide}

Constitui em uma síndrome com traço autossômico recessivo caracterizada por início precoce de hipertensão, hipocalemia, alcalose metabólica acompanhada por supressão da atividade da renina plasmática e ausência virtual de aldosterona circulante (6). Antagonistas do receptor mineralocorticóide promovem a diminuição da pressão arterial, sugerindo que outro mineralocorticóide circulante esteja presente. Estudos demonstraram que pacientes com esta síndrome mostram um defeito na conversão de cortisol para cortisona devido à ausência da enzima $11 \gamma$-hidroxiesteroide dehidrogenase (7). O significado deste achado permaneceu obscuro até a clonagem do receptor mineralocorticóide. In vivo, sabe-se que o cortisol apresenta concentração 100 vezes maior que a aldosterona, contudo quase toda a ativação do receptor mineralocorticóide está mediada pela aldosterona. Esta observação, combinada com os achados bioquímicos da Síndrome do excesso aparente de mineralocorticóide, sugere que a especificidade do receptor mineralocorticóide pela aldosterona é mediada indiretamente, com a $11 \gamma$-hidroxiesteroide dehidrogenase protegendo o receptor mineralocorticóide do cortisol, metabolizando-o para cortisona, o qual não ativa o receptor $(8)$. $\mathrm{Na}$ síndrome do excesso aparente de mineralocorticóide, a ausência desta enzima permite ao cortisol ativar o receptor mineralocorticóide, resultando em hipertensão mediada pelo aumento da atividade dos canais epiteliais de sódio. A confirmação da patogênese da Síndrome do excesso aparente de mineralocorticóide veio com a clonagem da $11 \gamma$-hidroxiesteroide dehidrogenase. Este gene é expresso nas mesmas células do néfron que expressam o canal epitelial de sódio, mostrando uma mutação homozigótica com perda de função em paciente com a Síndrome do excesso aparente de mineralocorticóide.

Em outras condições específicas como na ingestão crônica de grandes quantidades de alcaçuz, o que foi descrito acima também está envolvido na gênese desta forma de hipertensão, com supressão de renina e aldosterona devido à ação do metabólito do alcaçuz, o ácido gliceretiníco (9). Este metabólito é um potente inibidor da $11 \gamma$-hidroxiesteroide, produzindo uma fenocópia da Síndrome do excesso aparente de mineralocorticóide. De maneira similar, superprodução de cortisol por adenomas adrenais ou pituitário, bem como pela perda herdada do receptor de glucocorticóide, os altos níveis de cortisol suplantam a capacidade de a $11 \gamma$-hidroxiesteróide converter o cortisol em cortisona, resultando na ativação do receptor mineralocorticóide.

Além disso, outros esteróides, tais como a deoxicortisterona e a corticosterona, são potentes ativadores do receptor mineralocorticóide, mas normalmente níveis séricos muito baixos. Deficiências herdadas da $11 \gamma$-hidroxilase e da $17 \gamma$-hidroxilase prejudicam a biossíntese do cortisol, resultando em aumento da produção de deoxicortisterona e a corticos- 
terona, com conseqüente hipertensão e outras anormalidades (10).

\section{Hipertensão Exacerbada pela Gravidez}

Uma mutação no domínio ligante do receptor mineralocorticóide causa uma forma autossômica dominante de hipertensão que é caracteristicamente acelerada durante a gravidez (11). A mutação missense do receptor mineralocorticóide, denominada de $\mathrm{MR}$ S810L, demonstra ativação parcial na ausência de estímulo esteróide, mas com ativação normal pela aldosterona. Entretanto, componentes que normalmente ligam-se, mas não ativam o receptor mineralocorticóide, tais como a progesterona, são potentes agonistas do receptor mutante. Uma vez que os níveis de progesterona elevam-se cerca de 100 vezes durante a gestação, as pacientes portadoras da mutação desenvolvem hipertensão arterial grave neste período.

O mecanismo pelo qual o receptor MR S810L é ativado pela progesterona tem sido examinado por modelagem molecular e mutagênese sítio-dirigida. Os resultados sugerem que a troca de aminoácidos observada faz com que haja uma nova interação entre as hélices número 3 e 5 do receptor, resultando em mudança de conformação do mesmo e permitindo que moléculas como a progesterona, que normalmente se ligam mas não ativam o receptor, passem a fazê-lo. Uma vez que existem resíduos homólogos em vários outros receptores nucleares, hoje há grande interesse em investigar-se a abrangência deste mecanismo molecular como base de outras patologias.

\section{Sindrome de Liddle}

A síndrome de Liddle é caracterizada por uma transmissão autossômica dominante de penetrância variável, que promove o aparecimento de mutações nas sub-unidades $\gamma$ e $\gamma$ do canal epitelial de sódio, deletando a terminação $\mathrm{C}$ citoplasmática (figura 3 ). Estas mutações resultam no incremento da atividade do canal epitelial de sódio, atribuído em grande parte a um aumento no número de canais da superfície celular (12). Este aumento é devido a um aumento da meia-vida com conseqüente redução no clearance dos canais epiteliais de sódio nas células de superfície (13). Raras mutações missense em pacientes identificam o segmento na porção terminal C (PPPXY), que apresentam o mesmo fenótipo (14).

Em canais normais, o clearance da membrana é dependente da seqüência PPPXY na terminação citoplasmática $\mathrm{C}$ em ambas as sub-unidades $\gamma$ e $\gamma$ do canal epitelial de sódio. Perda desta seqüência na síndrome de Liddle resulta no prolongamento da meia-vida dos canais mutantes. Apesar de pouco compreendido, duas linhas de pesquisa estão atualmente em voga para estu-

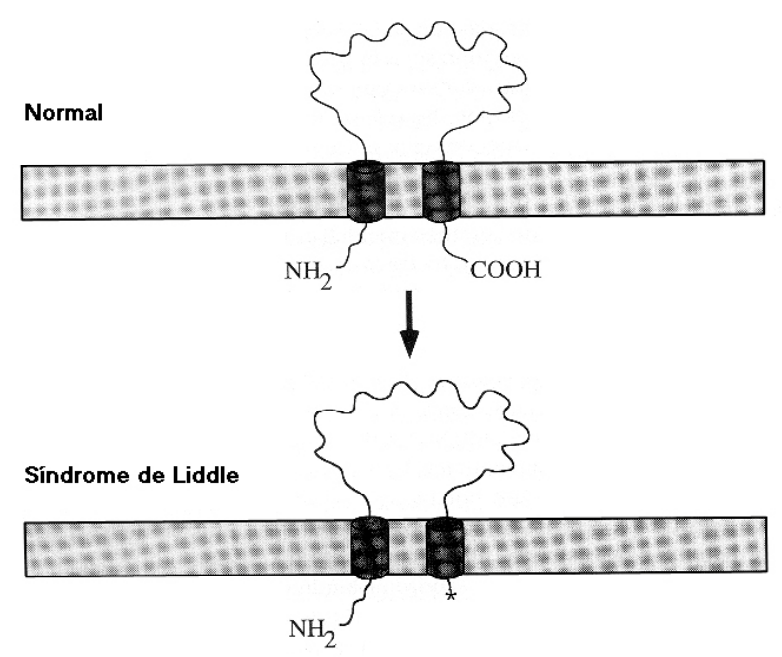

Figura 3. Base molecular da síndrome de Liddle. A regulação mineralocorticóide do canal epitelial de sódio renal é um hetero-oligômero composto de três sub-unidades. Mutações que truncam a terminação carboxi da subunidade $\gamma$ do canal leva à ativação do canal, resultando no aumento da reabsorção de sódio, expansão plasmática e hipertensão sal-sensível.

(adaptado de ref. 13)

dar os mecanismos envolvidos nesta etapa: 1) inibição da endocitose; 2 ) perda da interação com dois domínios WW contendo as proteínas Nedd4-1 e Nedd4-2, que participam da interação com a seqüência PPPXY das sub-unidades dos canais epiteliais de sódio.

Este aumento dos números dos canais epiteliais de sódio é suficiente para produzir hipertensão em humanos. O quadro clínico característico é de início precoce de hipertensão associada com alcalose hipocalêmica, atividade suprimida da renina plasmática e baixos níveis de aldosterona. Através de uma coletânea de casos e de análises de ligação (linkage analysis), os achados de hipertensão precoce foram atribuídos à participação de um segmento do cromossoma 16. Paralelamente, a determinação do gene codificador da sub-unidade $\gamma$ do canal epitelial de sódio localizado precisamente na mesma localização motivou os estudos como gene candidato para a síndrome de Liddle. A análise molecular desta subunidade revelou uma mutação pontual na arginina distal ao domínio transmembrana, transformando-a em um stop codon, truncando a proteína em 75 aminoácidos, mas deixando intacto o domínio transmembrana que constitui o poro funcional do canal (13).

A conseqüência das mutações, assim como em outras formas mendelianas de hipertensão, envolve o aumento preferencial no balanço de sal, através de uma excessiva reabsorção de sódio pelo canal epitelial de 
sódio no túbulo renal distal, podendo ser freqüente o achado de hipocalemia. Neste sentido, o tratamento com inibidores específicos desses canais, como o triantereno e a amilorida, pode reverter tanto a hipocalemia quanto a hipertensão, mas o mesmo não acontece com a espironolactona, um inibidor do receptor mineralocorticóide. Têm sido descritos casos isolados de pacientes com a síndrome de Liddle que se submeteram ao transplante renal como forma de tratamento (15).

\section{Feocromocitoma}

O feocromocitoma é um tumor neuroendócrino caracterizado por tecido cromafin e composto por grânulos neurossecretores contendo catecolaminas. São localizados predominantemente na medula adrenal, mas também podem ser encontrados nos gânglios do sistema nervoso simpático. Causam hipertensão que pode ser sustentada ou com caráter paroxístico pela alta secreção de catecolaminas. Múltiplas alterações genéticas têm sido associadas com o feocromocitoma. Embora estes tumores freqüentemente ocorram de forma esporádica, não herdada, alguns feocromocitomas apresentam características genéticas marcantes, podendo ser subdivididos em uma variedade de grupos: neoplasia endócrina múltipla (MEN 2), doença de von Hippel-Lindau (VHL), neurofibromatose tipo 1, paraganglioma hereditário, tumores relacionados ao gene succinate dehydrogenase subunit $\mathrm{D}$ (SDHD) e feocromocitomas hereditários com genes ainda não identificados (16). Em geral, feocromocitomas determinados geneticamente acometem pacientes mais jovens do que nas formas esporádicas.

Dentre os genes que têm sido implicados na iniciação e na progressão dos feocromocitomas incluemse oncogenes, genes supressores tumorais, genes do complexo mitocondrial II e SDHD.

\section{NEOPLASIA ENDÓCRINA MÚLTIPLA TIPO 2}

Constitui em uma síndrome com traço autossômico dominante que se subdivide em três grupos: 1) MEN 2A, que engloba o carcinoma medular da tireóide, feocromocitoma e o adenoma ou hiperplasia da paratireóide; 2) MEN 2B, definido pela presença do carcinoma medular da tireóide, feocromocitoma, habitus marfanóide e múltiplos neuromas da mucosa; e 3 ) carcinoma medular da tireóide familiar. De particular importância é que, na maioria dos casos, o feocromocitoma é bilateral e multifocal, sendo que esta característica clínica e anatomopatológica está relatada à origem genética do feocromocitoma associado a MEN
2. Todos os pacientes com MEN 2 apresentam mutações na linha germinativa no proto-oncogene RET, localizado no cromossoma 10q11.2. Este gene envolve 21 exons com 6 exons que apresentam mutações em mais de $97 \%$ dos pacientes (17). A função precisa do RET ainda é desconhecida, porém sabe-se que é expresso em tecidos derivados da crista neural, tais com as células cromafins e as células parafoliculares $\mathrm{C}$, estas com importante papel no desenvolvimento neuronal gastrointestinal e renal (18).

Mais de $85 \%$ dos pacientes com MEN 2A tem mutações no códon 634 do exon 10 do RET. Feocromocitomas na MEN 2 têm sido reportados com certas mutações no RET (16). Sabe-se que o risco para o desenvolvimento de feocromocitomas é alto na mutação do códon 634 em relação a outras mutações nos exons 10 e 11 (19).

\section{FEOCROMOCITOMA NA DOENÇA DE VON HIPPEL LINDAU TIPO 2}

A doença de von Hippel Lindau é um tumor com traço autossômico dominante que se pode apresentar com o feocromocitoma (tipo 2) ou sem o tumor (tipo 1). Esta última é a forma mais comum da doença, sendo caracterizada por predisposição ao desenvolvimento de angiomas retinianos, hemangioblastomas do sistema nervoso central e carcinoma renal de células claras. A tipo $2 \mathrm{~B}$ é a segunda mais comum, sendo constituída pelos achados da tipo 1 mais a presença de feocromocitomas. A tipo 2A é caracterizada pela predisposição ao desenvolvimento de feocromocitomas sem o carcinoma renal.

Estima-se que o feocromocitoma ocorra em cerca de 10 a $34 \%$ dos casos ( $50 \%$ são bilaterais), sendo a manifestação de apresentação da doença de Hippel Lindau em apenas 5\% (20).

Ao contrário do proto-oncogene RET, o gene da doença de von Hippel Lindau é supressor tumoral. Ele está localizado no cromossomo 3 p25-26, sendo que a maioria dos pacientes com feocromocitomas associados com a doença de von Hippel Lindau apresentam mutações missense. Mais de 300 mutações germinativas foram descritas, das quais 36 estão associadas com o feocromocitoma (16).

\section{FEOCROMOCITOMA NA NEUROFIBROMATOSE TIPO 1}

É a síndrome familiar mais comum de predispor ao feocromocitoma devido à sua ocorrência ( 1 em 4000 
indivíduos). Entretanto, o risco de feocromocitoma nestes casos é baixo (cerca de 2\%) (21).

Apresenta um traço autossômico dominante com expressão variável. A média de idade para o aparecimento do feocromocitoma é mais tardia que na MEN 2 e na doença de von Hippel Lindau, em torno da quinta década. O gene é um tumor supressor localizado no cromossomo $17 \mathrm{ql} 1.2$, sendo que os pacientes com feocromocitoma apresentam-se com a perda do alelo wild type.

\section{FEOCROMOCITOMA ESPORÁDICO}

A base genética para explicar a tumorogênese dos feocromocitomas esporádicos, bem como marcadores moleculares que permitam a distinção entre feocromocitomas benignos e malignos, permanece ainda por ser elucidada. Freqüentemente, os investigadores procuram em tumores aparentemente esporádicos por mutações dos genes que têm sido identificadas como causas para o surgimento de síndromes cancerígenas familiares, tais como o RET, doença de von HippelLindau neurofibromatose tipo 1 (16). Esta abordagem leva a novas definições de feocromocitomas não familiares relatados a mutações germinativas do SDHD. Contudo, o percentual de mutações somáticas dos genes que são conhecidos por serem responsáveis por síndromes cancerígenas familiares é baixo em formas não familiares de feocromocitomas, em torno de $8 \%$ para mutações do gene da doença de von Hippel-Lindau (22) e de 10 a 20\% para mutações do RET (23). Associado a isto, também são descritas perdas de alelos observadas em cromossomos de pacientes de formas familiares e não familiares de feocromocitoma. Análises futuras de feocromocitomas com técnicas de microarray e proteômica podem ajudar a responder a estas questões.

Embora o reconhecimento das formas mendelianas de hipertensão aqui descritas tenham uma enorme importância para o indivíduo, do ponto de vista populacional têm pouco impacto devido à raridade de acometimento. Entretanto, dois pontos merecem destaque: 1) o sub-diagnóstico é freqüente por não reconhecimento médico destas situações clínicas, e espera-se que este problema seja minimizado à medida que estes conhecimentos sejam incorporados à prática clínica; 2) a identificação destes defeitos raros representa uma oportunidade para evidenciar a importância de determinadas vias celulares que possam contribuir para a variação da pressão arterial e que participem da gênese da hipertensão arterial primária. Isto permitirá que os demais componentes destas vias celulares sejam investigados utilizando-se diferentes modelos experimentais ou para identificação de variantes genéticas destes genes para serem utilizadas em estudos de associação genética.

\section{REFERÊNCIAS}

1. Krieger JE. New contributions to clinical hypertension from molecular biology. Curr Opin Cardiol 1998; 13(5):312-6.

2. Sutherland DJ, Ruse JL, Laidlaw JC. Hypertension, increased aldosterone secretion and low plasma renin activity relieved by dexamethasone. Can Med Assoc J 1966;95(22):1109-19.

3. New MI, Peterson RE. A new form of congenital adrenal hyperplasia. J Clin Endocrinol Metab 1967;27(2):300-5.

4. Lifton RP, Dluhy RG, Powers M, Rich GM, Cook S, Ulick S, et al. A chimaeric 11 beta-hydroxylase/aldosterone synthase gene causes glucocorticoid-remediable aldosteronism and human hypertension. Nature 1992;355:262-5.

5. Chua SC, Szabo P, Vitek A, Grzeschik KH, John M, White $\mathrm{PC}$. Cloning of CDNA encoding steroid 11 beta-hydroxylase (P450c11). Proc Natl Acad Sci USA 1987;84(20):7193-7.

6. Lifton RP, Gharavi AG, Geller DS. Molecular mechanisms of human hypertension. Cell 2001;104(4):545-56.

7. Ulick S, Levine LS, Gunczler P, Zanconato G, Ramirez LC, Rauh W, et al. A syndrome of apparent mineralocorticoid excess associated with defects in the peripheral metabolism of cortisol. J Clin Endocrinol Metab 1979;49(5):757-64.

8. Funder JW, Pearce PT, Smith R, Smith AI. Mineralocorticoid action: target tissue specificity is enzyme, not receptor, mediated. Science 1988;242:583-5.

9. Stewart PM, Wallace AM, Valentino R, Burt D, Shackleton $\mathrm{CH}$, Edwards CR. Mineralocorticoid activity of liquorice: 11-beta-hydroxysteroid dehydrogenase deficiency comes of age. Lancet 1987;2821-4.

10. Kagimoto $M$, Winter JS, Kagimoto K, Simpson ER, Waterman MR. Structural characterization of normal and mutant human steroid 17 alpha-hydroxylase genes: molecular basis of one example of combined 17 alpha-hydroxylase/17,20 lyase deficiency. Mol Endocrinol 1988;2(6):564-70.

11. Geller DS, Farhi A, Pinkerton N, Fradley M, Moritz M, Spitzer A, et al. Activating mineralocorticoid receptor mutation in hypertension exacerbated by pregnancy. Science 2000;289:119-23.

12. Snyder PM, Price MP, McDonald FJ, Adams CM, Volk KA, Zeiher BG, et al. Mechanism by which Liddle's syndrome mutations increase activity of a human epithelial Na+ channel. Cell 1995;83(6):969-78. 
13. Shimkets RA, Warnock DG, Bositis CM, Nelson-Williams C, Hansson JH, Schambelan M, et al. Liddle's syndrome: heritable human hypertension caused by mutations in the beta subunit of the epithelial sodium channel. Cell 1994;79(3):407-14.

14. Hansson JH, Schild L, Lu Y, Wilson TA, Gautschi I, Shimkets R, et al. A de novo missense mutation of the beta subunit of the epithelial sodium channel causes hypertension and Liddle syndrome, identifying a proline-rich segment critical for regulation of channel activity. Proc Natl Acad Sci USA 1995;92(25):1 1495-9.

15. Botero-Velez M, Curtis JJ, Warnock DG. Brief report: Liddle's syndrome revisited - a disorder of sodium reabsorption in the distal tubule. N Engl J Med 1994;330(3): 178-81.

16. Koch CA, Vortmeyer AO, Huang SC, Alesci S, Zhuang Z, Pacak K. Genetic aspects of pheochromocytoma. Endocr Regul 2001;35(1):43-52.

17. Pacak K, Linehan WM, Eisenhofer G, Walther MM, Goldstein DS. Recent advances in genetics, diagnosis, localization, and treatment of pheochromocytoma. Ann Intern Med. 2001;134(4):315-29.

18. Schuchardt A, D'Agati V, Larsson-Blomberg L, Costantini $F$, Pachnis V. Defects in the kidney and enteric nervous system of mice lacking the tyrosine kinase receptor Ret. Nature 1994;367(6461):380-3.

19. Mulligan LM, Eng C, Healey CS, Clayton D, Kwok JB, Gardner E, et al. Specific mutations of the RET protooncogene are related to disease phenotype in MEN 2A and FMTC. Nat Genet 1994;6(1):70-4.
20. Walther MM, Reiter R, Keiser HR, Choyke PL, Venzon D, Hurley $\mathrm{K}$, et al. Clinical and genetic characterization of pheochromocytoma in von Hippel-Lindau families: comparison with sporadic pheochromocytoma gives insight into natural history of pheochromocytoma. J Urol 1999; 162(3 Pt 1):659-64.

21. Huson SM, Compston DA, Harper PS. A genetic study of von Recklinghausen neurofibromatosis in south east Wales. II. Guidelines for genetic counselling. J Med Genet 1989;26(11):712-21.

22. Bender BU, Gutsche M, Glasker S, Muller B, Kirste G, Eng $C$, et al. Differential genetic alterations in von Hippel-Lindau syndrome-associated and sporadic pheochromocytomas. J Clin Endocrinol Metab 2000;85(12):456874.

23. Eng C, Crossey PA, Mulligan LM, Healey CS, Houghton $C$, Prowse A, et al. Mutations in the RET proto-oncogene and the von Hippel-Lindau disease tumour suppressor gene in sporadic and syndromic phaeochromocytomas. J Med Genet 1995;32(12):934-7.

24. Lifton RP, Dluhy RG, Powers M, Rich GM, Gutkin M, Fallo $F$, et al. Hereditary hypertension caused by chimaeric gene duplications and ectopic expression of aldosterone synthase. Nat Genet 1992;2(1):66-74.

Endereço para correspondência:

José Eduardo Krieger

Laboratório de Genética e Cardiologia Molecular do

InCor

Hospital das Clínicas, Universidade de São Paulo

Av. Dr. Enéas de Carvalho Aguiar 44

05403-00 São Paulo, SP

e-mail: krieger@incor.usp.br 